\title{
Biografias de imigrantes poloneses que se tornaram nomes de endereços na cidade de Curitiba -
}

\author{
Rafaela Mascarenhas Rocha ${ }^{1}$ \\ Recebido em maio de 2019 \\ Aceito em outubro de 2019
}

\section{RESUMO}

Este artigo é parte da amostra dos dados coletados em pesquisa junto a membros do grupo de imigrantes poloneses em Curitiba, que emprestaram postumamente seus nomes para endereços na capital paranaense. Trazemos aqui algumas informações referentes às biografias de dez imigrantes que atualmente são nomes de ruas em Curitiba, a localização de cada uma dessas ruas, uma descrição sobre os logradouros - quanto à extensão, se são vias de transporte coletivo, se são áreas comerciais ou predominantemente residenciais e outras características - e também ainda há informações sobre o processo de oficialização de cada um deles junto ao poder público municipal. Neste artigo não serão problematizadas questões como, por exemplo, se há uma lógica para as homenagens, que obedeça a uma relação de importância entre homenageado e logradouro, ou níveis diferentes de prestígio entre os homenageados, pois essas são informações ainda em processo de análise em um estudo maior. As trajetórias aqui apresentadas serão as seguintes: Edmundo Saporski, Jerônimo Durski e Madame Curie (Maria Sklodowska).

Palavras-chave: Biografias; polono brasileiros; ruas; Curitiba.

\begin{abstract}
This paper is a part of the sample of the data collected in a research with members of the polish immigrant group on Curitiba who posthumously lent their names to addresses in the city. Here we bring some information concerning the biography of ten immigrants that gave their names to streets in Curitiba, nowadays. We present the location of each one of the streets and some description about them their length, if they are public transportation routes, or if those streets are commercial or residential areas, and other features. There is also some information about the process of formalization in each one of the addresses in the government. In this paper we are not going to discuss certain questions, for example: about if there is a logic involving these kinds of honors, as the relationship of importance between the immigrant who is honored and the street named with the his or her name, or different levels of prestige between the immigrants honored - because these are information still in a process of analysis, in a major study. The trajectories presented here belong to the following immigrants: Edmundo Saporski, Jerônimo Durski and Madame Curie (Maria Sklodowska).
\end{abstract}

Keywords: Biographies; Polish-Brazilian; Streets; Curitiba.

${ }^{1}$ Bacharel em Ciências Sociais e Mestra em Sociologia pela Universidade Federal do Paraná (UFPR), atualmente é doutoranda em Sociologia pela UFPR. Recebe apoio financeiro da CAPES. Email: rafaela_mrocha@yahoo.com.br 


\section{Introdução}

A imigração polonesa na região de Curitiba possibilitou vários estudos no campo da história como em Wachowicz (1976, p.12; 2000, p. 107-146) e Boschilia (2004, p. 63), por exemplo, obras nas quais os autores apresentam levantamentos históricos detalhados sobre a chegada do grupo às áreas de colônias, além de contar como era a vida cotidiana desses imigrantes na terra de adoção. Para além desses, há também muitos trabalhos em áreas como o turismo, um exemplo é o de Bahl (1994, p. 21-32) que identifica a identidade polonesa como um potencial para atrativo turístico na cidade. Mas é com o olhar voltado para a sociologia que podemos avançar nas discussões feitas desde Ianni (1966, p. 117-146) quando verificou a maciça presença polonesa em Curitiba, e como ela era tratada pela população local até a primeira metade do século XX; ou em Oliveira (2010, p. 83-99) quando indica uma saída para a ressignificação da presença polonesa em Curitiba, apresentando aos leitores que além do trabalho rural o grupo - mais numeroso entre os imigrantes europeus e asiáticos no estado do Paraná - se organizara em torno de um extenso número de instituições sociais construídas e mantidas pelos poloneses na cidade, tais como: jornais, escolas, clubes esportivos e artísticos, debatendo com Ianni (1966, p. 117-146) o quanto era ilógico o estigma negativo colocado sobre este grupo. A desconstrução deste estigma aparece tanto na obra de Ianni (1966, p. 117-146) e que serve-nos agora, como ponto de partida para pensarmos posições de prestígio dos imigrantes poloneses em Curitiba. Pois, se consideramos a presença de polono brasileiros ilustres na vida curitibana, como: médicos, engenheiros, professores, escritores, políticos entre outras profissões, e que ao exercerem suas profissões e ao serem reconhecidos pelos seus feitos após suas vidas - recebendo homenagens na cidade - elevam o nome da comunidade polono brasileira e desfazem ainda mais aquele primeiro estigma detectado por Ianni (1966, p. 117-146), algo que não acreditamos existir mais atualmente.

O mecanismo de se prestar homenagem a um antepassado vem sendo utilizado pelos descendentes de poloneses em Curitiba e pela comunidade curitibana, de maneira geral, desde a metade do século XX (ROCHA, 2016, p. 115). Isso pode ser entendido como 
uma maneira de perpetuar os legados dos antepassados, de prestar reconhecimento às trajetórias e também de destacar nos espaços públicos da cidade a presença deste grupo de imigrantes. Foram observados entre os homenageados com endereços, nomes de imigrantes ilustres para a história da cidade; para o grupo polono brasileiro de maneira localizada, ou seja, dentro dos bairros; e ou até mesmo em nível internacional. Os prestadores das homenagens são agentes do poder público municipal: vereadores ou prefeitos, que aprovam os nomes dos homenageados que se tornarão oficialmente denominações de endereços através de projetos de lei que tramitam na Câmara Municipal ou, em alguns casos, por decreto. Ainda segundo trabalho anterior que vem ganhando sequência (ROCHA, 2016, p. 83) os endereços com nomes de polono brasileiros acontecem em 6o dos 75 bairros de Curitiba, indo muito além dos territórios das antigas colônias, que atualmente são bairros nas regiões norte e oeste da cidade. Em números, de um total de 8034 logradouros públicos, 421 possuem nomes de polono brasileiros, ou seja, $5 \%$ do total. Com destaque para o bairro Cidade Industrial de Curitiba, que possui 49 endereços com nomes de polono brasileiros.

Para além de maiores apontamentos teóricos sobre o movimento de prestar e receber homenagens, ou quanto ao estudo de reconhecimento de legados dos antepassados, este artigo tem por objetivo analisar biografias de quatro dos polono brasileiros homenageados. Isto permite verificar o peso de seus legados na hora da escolha de seus nomes para oficializar um endereço. E mais, se compararmos os legados entre si, pode-se perceber trajetórias com níveis diferentes de destaque. Quer dizer, pode-se observar assim, se um imigrante era alguém muito popular no bairro, ou na colônia, ou se era alguém reconhecido nacionalmente em uma área profissional específica, ou ainda se a pessoa teve notoriedade internacional devido à sua trajetória e sua carreira. Não se trata de comparar maiores ou menores importâncias, mas sim verificar os diferentes tipos de pessoas que mereceram um nome em alguma rua. Para que, assim, se compreenda melhor o mecanismo de prestação de homenagens, através do pensamento que questiona: o homenageado é importante para quem, ou para que grupo de pessoas? Em que medida sua trajetória pode valer uma homenagem como essa? Essa é a maior honraria que se pode prestar postumamente? 
De maneira inicial, fazemos uma exposição sobre como a denominação de endereços para homenagear antepassados da imigração polonesa, especificamente, é pertinente e frequente na cidade de Curitiba. As relações entre a vida do imigrante e o bairro onde sua rua se encontra; ou a importância em termos de hierarquia social do imigrante em sua trajetória e o porte da rua que leva seu nome; e por último, se houve e qual era a relação entre o homenageado e o prestador da homenagem, são elementos que ainda estão sendo fruto de análise, dentro de uma pesquisa maior. Portanto, nos concentraremos em apresentar a ocorrência desta forma de homenagem e como isso pode ser um sujeito de estudo dentro do campo da Sociologia, e também a relação entre a concentração de ruas que levam nomes de poloneses e as áreas da cidade onde eles ocuparam no passado, mostrando que há uma relação nisso e a possibilidade de um reduto polonês em Curitiba. As informações aqui apresentadas dão conta dos nomes das ruas, trajetórias dos homenageados, os bairros onde ficam os endereços e um retrato de como é cada um deles. Pois acreditamos que, desta forma se compreenda se houve uma lógica utilizada pelos agentes públicos ao prestar cada uma das homenagens e qual foi ela: se foi uma demanda da comunidade, se foi uma prestação pessoal de homenagem, ou um nome que surgiu ao acaso entre as diversas ruas precisando de um nome, inúmeras são as possibilidades.

Os endereços a serem apresentados neste artigo serão: Rua Edmundo Saporski, Rua Jerônimo Durski, Rua Julio Szymanski e Rua Madame Curie (Maria Sklodowska) e as respectivas descrições sobre trajetórias de cada homenageado e características das ruas. Cada descrição acompanha uma imagem da rua, para uma melhor visualização do endereço trabalhado.

\section{Nomes de ruas: processos de oficialização}

Pelas cidades brasileiras - e Curitiba não foge a esta regra - existem milhares de nomes de endereços que fazem referências diversas, tais como datas importantes: a exemplo da Avenida Nove de Julho na cidade de São Paulo e da Praça Sete de Setembro em Belo Horizonte; nomes em alusão à religiosidade: como a Avenida Nossa Senhora de Copacabana no Rio de Janeiro; ou também em referência a outros países: como a 
Avenida República Argentina em Curitiba. No entanto, a grande maioria dos endereços levam nomes de pessoas, podendo ser comprovado pelo caso de Curitiba em que são cerca de $80 \%$ dos 8034 endereços que trazem o nome de alguma figura ilustre, como os exemplos da Avenida Presidente Kennedy ou da Alameda Dom Pedro II.

Dentre os nomes de endereços encontram-se homenageados de diversos ramos profissionais, épocas da história e nacionalidades. Contudo, uma importante curiosidade em relação a este tema é a de que, de maneira geral nas ruas das cidades brasileiras, há muito mais nomes masculinos do que femininos denominando os endereços. Alguns endereços marcantes aparecem como a Rua Clara Nunes, no bairro de Madureira no Rio de Janeiro, a Rua Augusta no centro de São Paulo ou a Avenida Anita Garibaldi no bairro Juvevê, em Curitiba são exemplos de locais com nomes femininos, mas são exceções. O que pode indicar mais um ramo de pesquisa para colegas da área, futuramente.

De maneira geral, a denominação de um endereço é uma homenagem póstuma, salvo em períodos antidemocráticos ${ }^{2}$. A proposta para oficializar um nome de endereço surge como projeto de lei, geralmente dentro do poder legislativo local - a Câmara Municipal. Vereadores proponentes elaboram o projeto para denominar uma ou mais ruas ao mesmo tempo, em casos de inauguração ou abertura de conjuntos habitacionais, no entanto esses projetos não trazem detalhes sobre as homenagens nem as razões para tal. Para ser aprovado, o projeto de lei passa por Comissões dentro da Casa, grupos de trabalho onde os vereadores discutirão a constitucionalidade do projeto, fazer ajustes quando necessário, ou incluir adendos. No caso dos nomes de rua em Curitiba, a Comissão que discute o tema é a de Educação e Cultura, onde além de receber projetos de lei de vereadores, de maneira individual, também se elabora projetos coletivos, onde vereadores que concordam com uma denominação, ou com um bloco de denominações, elaboram juntos um projeto de lei. Ao ser aprovado ou ajustado na Comissão de Educação e Cultura, o projeto vai para a Comissão de Constituição e Justiça, onde se discute se há legalidade nos nomes propostos, se nenhum dos homenageados fere direitos humanos, por exemplo, ou se não há repetição na homenagem. Para que então o

2 Um exemplo de denominação de espaço público como homenagem em vida é percebido no período da ditadura militar brasileira (1964-1985) quando o ex-prefeito de Curitiba Omar Sabbag recebe ainda em vida a homenagem de uma escola com seu nome no bairro Cajuru, no início dos anos 1970. 
projeto vá ao plenário da Casa ser aprovado pelo conjunto dos vereadores. Em geral, os nomes de ruas aqui estudados são aprovados de maneira consensual e rápida. Por fim, o projeto de lei é encaminhado para o prefeito, que sanciona a lei e a faz cumprir. Algumas das ruas aqui estudadas foram oficializadas por meio de decretos do prefeito, ou seja, denominação elaborada e sancionada por ele sem que passasse pelo Poder Legislativo Municipal, o que pode significar duas coisas: a primeira é que aquela era uma demanda particular do prefeito, como um desejo político seu; ou pode-se tratar de mais uma das fases de ruptura democrática que o Brasil teve, onde se anula o poder legislativo.

\section{Polono brasileiros em nomes de ruas: iniciativas e oficializações}

A Sociologia da Imigração se apresenta como um campo de pesquisa que dialoga muito com a história dos grupos que imigraram e imigram, principalmente no caso brasileiro. O texto de Seyferth (1999, p. 220) é exemplo de trabalho que trata sobre a Lei de Nacionalização imposta pelo governo Getúlio Vargas - proibindo, entre outras coisas, o uso de língua estrangeira em espaços públicos de todo o país - e que veio acarretar em transformações drásticas nas vidas dos estrangeiros no Brasil, como o fim das associações e das escolas em idiomas de suas terras de origem. Os estrangeiros em Curitiba que foram afetados pela Lei de nacionalização eram principalmente aqueles de origem germânica e italiana, pois eram protagonistas dos Estados de exceção na Europa, e que assim como o Japão formaram o Eixo durante a II Guerra Mundial. No entanto, isso não impediu que o rechaço chegasse a populações eslavas, como o desmonte de clubes e de jornais escritos em polonês na cidade de Curitiba, como traz Oliveira (2010, p. 83-99).

Sobre o grupo de imigrantes poloneses no Paraná, é importante citar o artigo “Do Polonês ao Polaco”, de Octavio Ianni (1966, p. 117-146) que se tornou um capítulo em Raças e Classes Sociais no Brasil, este por sua vez, relatava um contexto da imigração polonesa em seu tempo presente. Quando trabalhando em Curitiba na década de 1960, o sociólogo se deparou com um grande estigma negativo e preconceito bastante presente, que a comunidade curitibana nutria pelos poloneses que aqui viviam. Esta população de imigrantes era tratada como indesejável para relações afetivas, dispensáveis para 
trabalhos que exigissem mais intelecto do que força braçal, pois eram taxados como analfabetos, alcoolistas, que teriam eles predileção pelos trabalhos domésticos, que tinham dificuldade em aprender a língua portuguesa e eram apegados em demasia à religião e às orientações dos padres. E assim, o autor viu que uma comparação entre poloneses e negros era inevitável por parte da comunidade local: "Constitui-se ali toda uma doutrina de inferioridade moral e intelectual do polonês, como se formara com a escravatura a doutrina da inferioridade inata do africano ou seu descendente." (IANNI, 1966, p. 56).

Em estudo anterior (ROCHA, 2016, p. 14), verifica-se uma notável presença de endereços na cidade de Curitiba que tem nomes de algum polono brasileiro: tanto imigrantes quanto descendentes. E ao investigar o processo de oficialização desses endereços, verificou-se também, que grande parte desses nomes foi oficializada por dois vereadores em especial, são eles: José Gorski entre os anos 1970 e 2000 e Tito Zeglin a partir dos anos 1980 até o presente. Ambos são de origem polonesa, se consideram como representantes do grupo na Câmara Municipal de Curitiba e tem ou teve - no caso de José Gorski - como prioridade elevar o nome da comunidade através do trabalho no legislativo, para além somente da denominação de logradouros. Como por exemplo, títulos de cidadão honorário a outros membros do grupo e melhorias na infraestrutura urbana nas proximidades da Igreja de Santo Estanislau, no centro da cidade, local de concentração do grupo, pois realiza missas em idioma polonês até os dias atuais, entre outros projetos e leis.

Dentre os resultados encontrados até o momento, pode-se afirmar que a denominação de ruas com nomes de algum antepassado polono brasileiro seja um mecanismo de prestação de homenagem por parte dos congressistas, e em especial Gorski e Zeglin. Algo que reforce a presença polonesa na cidade, ressaltando sua importância no cenário local, como o maior grupo de imigrantes a se instalar na cidade (OLIVEIRA, 2010, p. 83-99) e que reforça também, consequentemente, as trajetórias individuais, levando a pensar que esse mecanismo de prestação de homenagem passe por critérios referentes à trajetória, em que possa haver alguns polono brasileiros mais e outros menos aptos a receber tal honraria. Contudo, esta reflexão não está concluída e não será apresentada no presente artigo, pois necessita de maior arcabouço teórico 
dentro da linha de uma Sociologia das Homenagens. Porém para começar a traçar este raciocínio, nos voltamos para as biografias dos homenageados com endereços para entender se há um padrão de trajetórias, que marque também um padrão de homenagens, ou se há heterogeneidade, o que possibilita, então, variar as razões para que os prestadores das homenagens às façam.

\section{Trajetórias de polono brasileiros que viraram nomes de ruas em Curitiba}

A cidade de Curitiba tem quatro bairros que foram colônias exclusivamente polonesas no passado, são eles: Abranches, Orleans, Santa Cândida e Santo Inácio. Em todos eles o índice de ruas com nomes de poloneses é alto, no bairro Orleans são 18 ruas e no bairro Santa Cândida 24, mas não somente nesses. Há também bairros de urbanização recente (anos 1970) como o Cajuru, Cidade Industrial e Sítio Cercado que também contam com alto número de endereços que homenageiam poloneses, somente na CIC são 51 endereços com nomes de poloneses. Dos 8034 logradouros na cidade, 421 levam o nome de algum polono brasileiro segundo dados levantados por Rocha (2016, p. 86)3 ${ }^{3}$, nomes que estão presentes em 6o dos 75 bairros de Curitiba. Apresentamos a seguir alguns dos nomes de imigrantes ou descendentes de poloneses que foram agraciados com seus nomes em algum endereço na cidade.

A primeira biografia a ser apresentada é a de Edmundo Saporski, imigrante nascido em Siolkowice, Polônia em 1844. Pioneiro da imigração polonesa ao Brasil, Saporski chamava-se Sebastião Edmundo Wós Saporski, quando muda de nome para desertar do exército da Prússia e emigra rumo ao continente americano (WACHOWICZ, 200o, p. 107-146). No Paraná, trabalhou como agrimensor e ajudou imigrantes e governo local com a divisão de terras para abertura de novas colônias. Escreveu para a Gazeta Polska e foi membro da Sociedade Tadeusz Kosciusko. Viveu até 1933. A rua que leva seu nome fica no bairro Mercês, e foi oficializada em 1951 por iniciativa do vereador Edvino Donato Tempski. Sendo a primeira via em Curitiba a ter o nome de algum polono

3 Uma atualização destes dados está sendo feita em pesquisa mais recente. No qual o número de logradouros da cidade já aparece consideravelmente maior e, consequentemente, o de homenageados também. Porém sua divulgação ainda não pode ser feita, devido ao andamento do seu processo de apuração. 
brasileiro. Inclusive, foi no bairro do Mercês que Saporski se instala e vive a maior parte de sua vida, o bairro foi uma colônia mista que recebeu alguns alemães, poloneses e ucranianos. A localização da rua - um bairro central e que foi antiga colônia - e a data de sua oficialização, são aspectos que podem mostrar a ideia de homenagear o representante da imigração polonesa, demarcar essa região como um reduto da presença polonesa e abrir espaço para que outras homenagens desta natureza fossem feitas, como de fato foram.

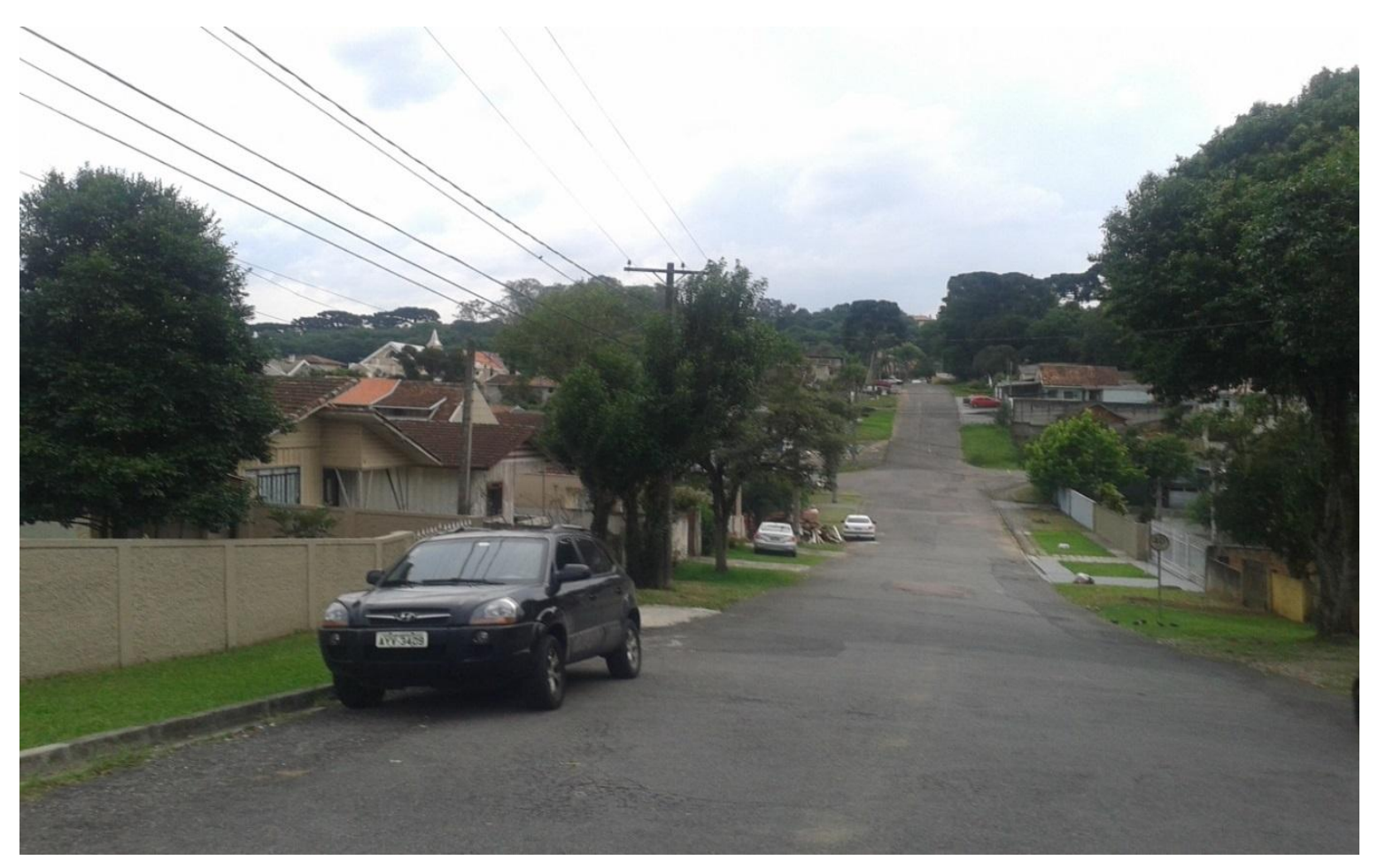

Figura 1: Rua Edmundo Saporski, no bairro Mercês

Em seguida, temos Jerônimo Durski, uma rua que passa pelos bairros Bigorrilho e Campina do Siqueira, que se tornou via oficial da cidade de Curitiba em dezembro de 1954, através de decreto do então prefeito Ernani Santiago Oliveira. Durski foi um imigrante nascido em Poznan, em 1824, trabalhou como professor a vida toda. Era conhecido como um mestre rígido, e muito procurado pelas escolas coloniais de Curitiba, tendo trabalhado na escola do Orleans entre os anos de 1890 e 94 (WACHOWICZ, 1976, p. 39). Trabalhou em diversas escolas em áreas rurais, ou urbanas, como no bairro do Batel em Curitiba, ou nas cidades do interior do Paraná como na 
Lapa, lecionando em polonês nas colônias ou em português, pois havia se naturalizado brasileiro ${ }^{4}$. Ele foi uma liderança comunitária, que exigia dos pais a presença das crianças na escola; e do governo, a melhoria da estrutura das colônias e das escolas coloniais. Viveu até 1905. A iniciativa de denominar uma das principais vias da região do Campina do Siqueira com o nome de Durski, provavelmente venha a ser um sinal de reconhecimento da trajetória individual, como também a referência ao grupo polono brasileiro em Curitiba, pois essa homenagem é feita três anos após a de Saporski, parecendo ser esse o início do reconhecimento ao grupo.

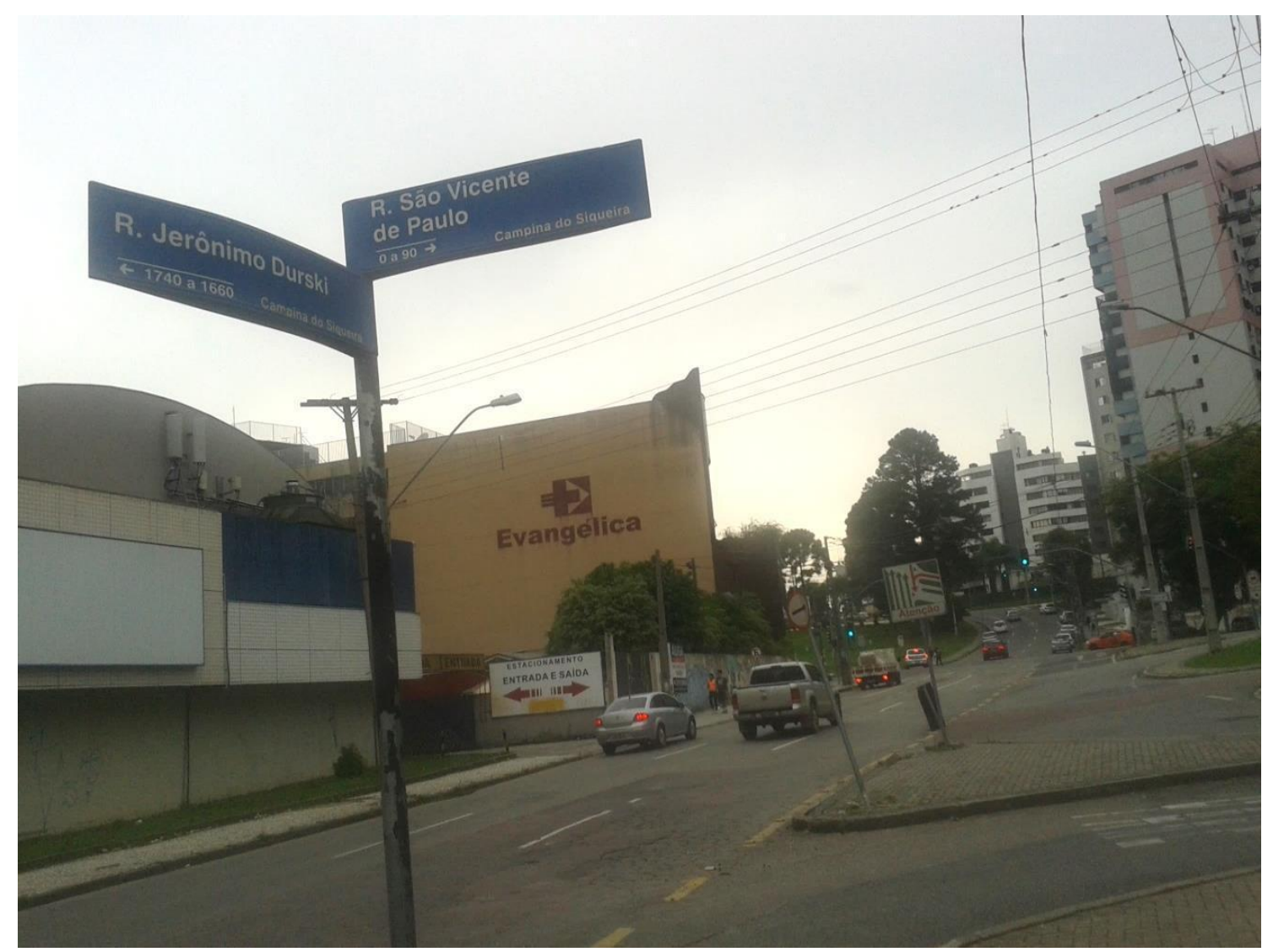

Figura 2: Rua Jerônimo Durski, no bairro Campina do Siqueira

Em seguida, apresentamos o Largo Júlio Szymanski, um imigrante que viveu entre os anos de 1870 e 1975, nascido em Kielce, Polônia. Szymanski foi um oftalmologista e professor da área de medicina, sendo um dos fundadores da UFPR,

4 A fonte consultada não deixa claro se esse movimento "naturalização" de Durski teria sido uma solicitação de cidadania ou de nacionalidade brasileiras, visto que são pedidos diferentes de acordo com a legislação do século XX, não nos permitindo saber se assim o era também no século XIX. 
porém ele não se fixa em Curitiba, trabalha também no Rio de Janeiro. Esse é o terceiro dos endereços selecionados aqui, que foi oficializado através de decreto do prefeito, e neste caso foi um decreto assinado por Omar Sabbag, em abril de 1970. Importante ressaltar que o período de oficialização deste espaço público coincide com um dos anos mais rígidos da ditadura militar brasileira, ${ }^{5}$ e Sabbag foi eleito prefeito por indicação do executivo estadual, os chamados prefeitos "biônicos”. O Largo é uma pequena área rodeada por três ruas muito movimentadas no bairro Rebouças: a Avenida Marechal Floriano Peixoto, a Avenida Presidente Kennedy e a Rua Almirante Gonçalves, o que pode indicar que o logradouro está ali colocado para valorizar ainda mais a trajetória de Szymanski, valorizando um dos fundadores da UFPR entre vários chefes de Estado, e em uma região central da cidade e que não teve qualquer ligação com a imigração polonesa.

5 Após a imposição do AI-5, manteve-se eleições para os poderes legislativos - vereadores, deputados e senadores - mas não para prefeitos de capitais e de cidades consideradas "estratégicas", a exemplo de Foz do Iguaçu-PR, tendo então as indicações pelos governadores dos estados. Fonte: <http://arte.folha.uol.com.br/especiais/2014/o3/23/o-golpe-e-a-ditadura-militar/a-abertura.html>.

Acesso em: 17/04/2019. 


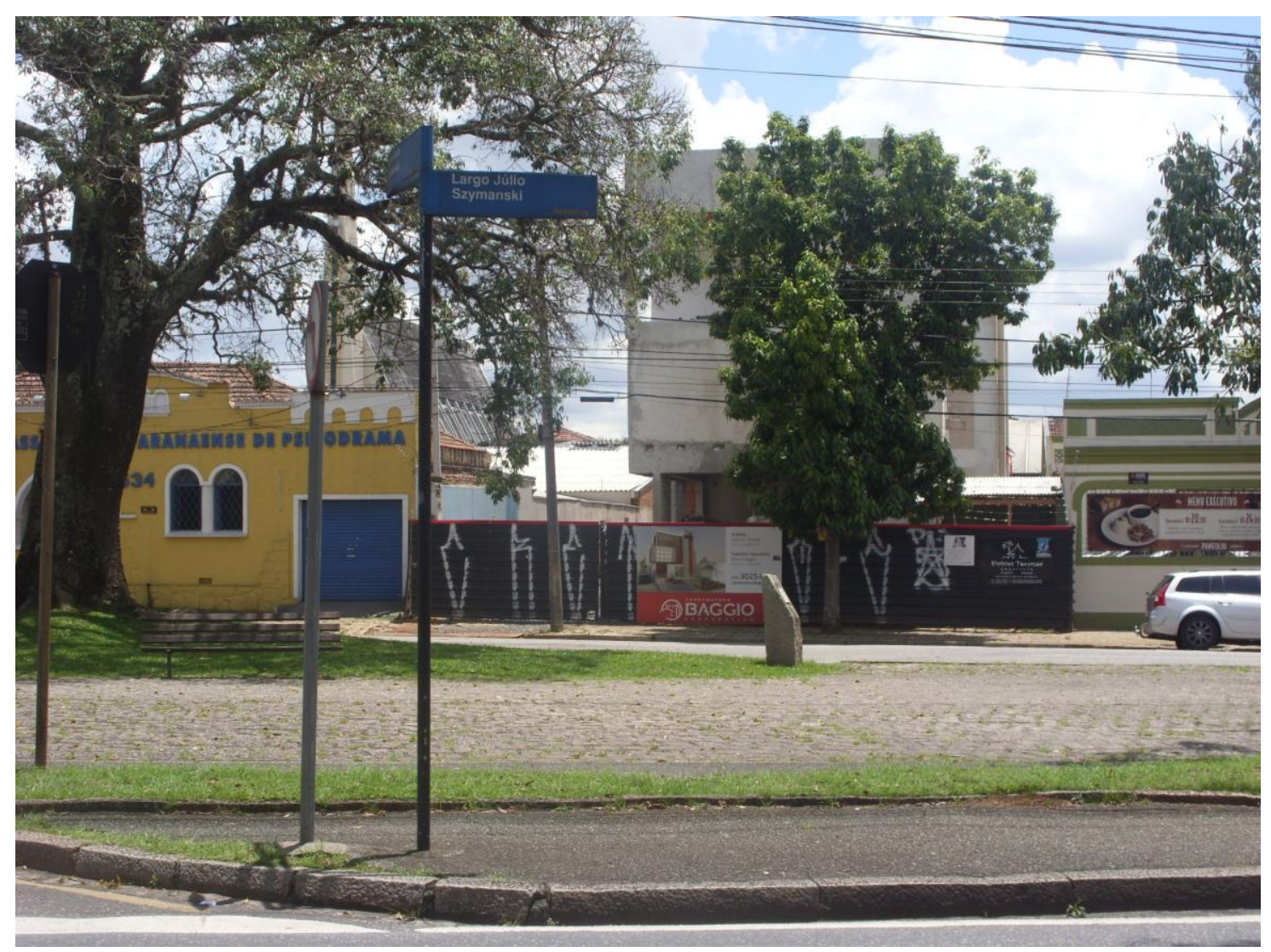

Figura 6: Largo Julio Szymanski, no bairro Rebouças

E o último exemplo aqui listado leva o nome de polonesa que não foi imigrante em Curitiba, mas em Paris. Madame Curie (Maria Sklodowska) nasce em Varsóvia, em 1867 e emigra para a França para fazer seus estudos em ciências. Descobre elementos químicos capazes de emitir radiações, os quais ela batiza de Polônio (em homenagem à sua terra natal) e Rádio, e com esses descobrimentos Curie ganha dois prêmios Nobel, um em Química e um em Física, além de ser a primeira mulher a obter o título de doutora pela Universidade de Sorbonne, lecionando também por essa instituição. Curie faleceu em 1934, em decorrência de uma leucemia, causada pela exposição excessiva aos elementos que ela mesma descobrira. Hoje, seus restos mortais jazem no Panthéon de Paris, sendo a única imigrante lá sepultada entre os grandes heróis da França. A rua com seu nome está localizada no Jardim Piratini, no bairro Pinheirinho, e foi oficializada por projeto de lei de autoria da Comissão de Educação e Cultura da Câmara Municipal, em dezembro de 1981, com outras cinco ruas. Isso pode indicar que não se trata exatamente de uma homenagem direcionada à personalidade de Marie Curie, mas um nome que 
surge em meio a tantos outros para contemplar o endereço que precisava de nome na ocasião. Talvez até devido à distância que essa personalidade tem em relação à vida na cidade, a homenagem acaba relacionando-se muito mais ao importante nome das ciências exatas do que uma marca dos polono brasileiros na cidade.

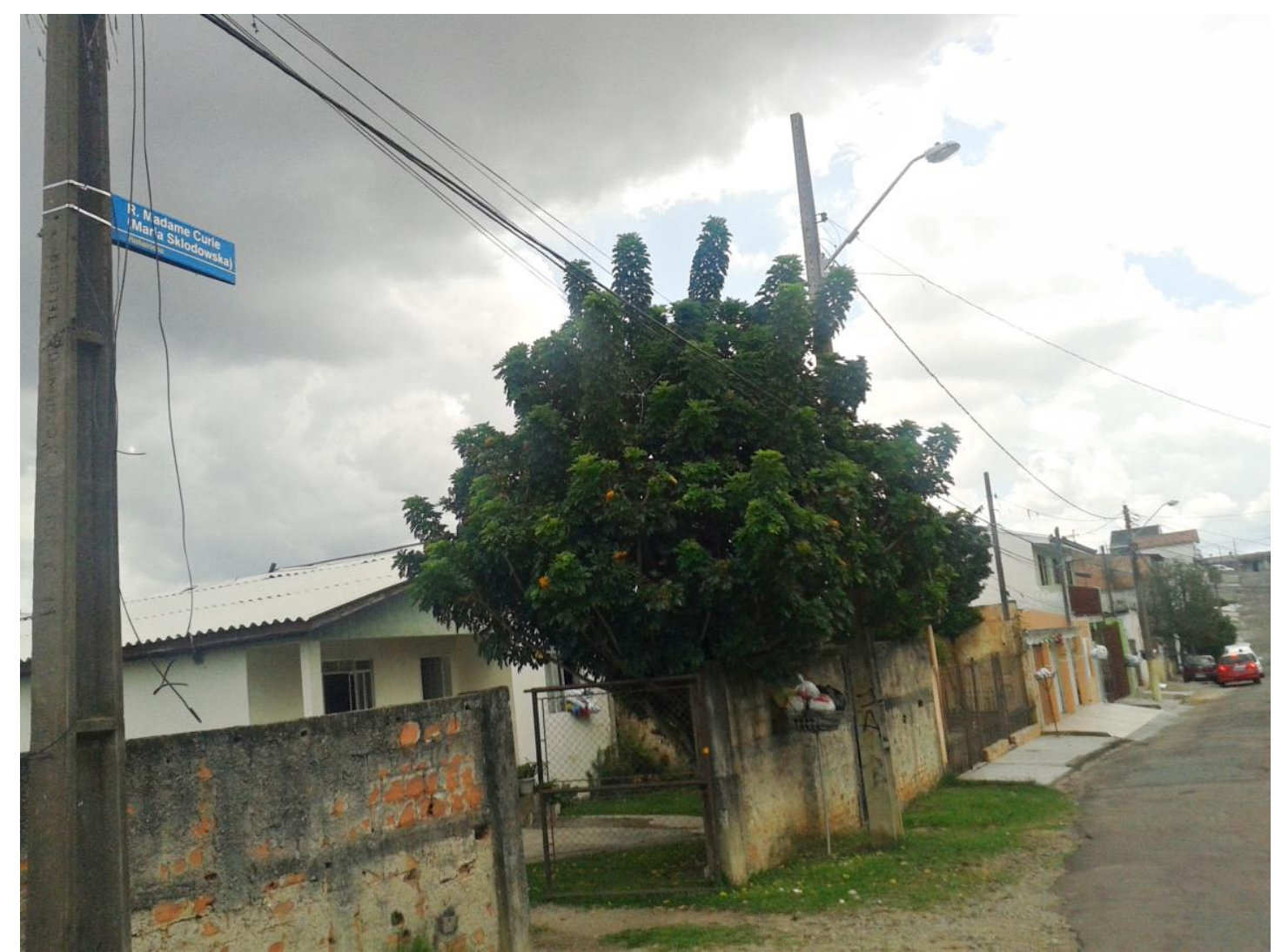

Figura 3: Rua Madame Curie (Maria Sklodowska), no bairro Pinheirinho

\section{Considerações finais}

O histórico da imigração polonesa na região leste do Paraná, e em especial na cidade de Curitiba mostra uma presença intensa por toda a cidade, e uma concentração bastante expressiva nas regiões que foram antigas colônias, e que atualmente são bairros da região norte e oeste da capital paranaense. Em quase 150 anos de imigração, este grupo consegue utilizar-se das denominações de endereços para demarcar seus redutos, afirmar sua presença e homenagear seus antepassados ilustres. Isso é perceptível através dos números coletados neste estudo. 
Os quatro polonos brasileiros que tiveram suas trajetórias apresentadas aqui são pessoas das mais diversas origens e ramos profissionais, também divididos entre imigrantes e descendentes, homens e mulheres. Com essa pequena amostra, é possível verificar o quanto o grupo polono brasileiro é heterogêneo, a começar por aqueles que tiveram seus nomes eternizados nas ruas da cidade. Desta forma, é possível pensar que não estão somente localizados nos trabalhos rurais, como se discutia outrora, ou também que se diferenciam de outros grupos que se concentraram em trabalhos urbanos, somente.

E pensando sobre as localizações dos endereços, é possível verificar que se em um primeiro momento houve maior concentração da população polono brasileira nas áreas das ex-colônias, e é portanto, aceitável denotar que esses espaços possam ser redutos da imigração, a amostra indica também que a ferramenta de denominação de endereços extrapola os limites das ex-colônias, espraiando a presença polono brasileira e afirmando este como o grupo de imigrantes mais numeroso da cidade. Sobre os processos de oficialização, o que se vê é a divisão das iniciativas entre poder legislativo e executivo. Pois se em um primeiro momento, compreende-se esta pauta como sendo um trabalho dos vereadores, exclusivamente, nota-se entre os exemplos aqui citados uma forte interferência da prefeitura nas escolhas das denominações. E os motivos em que se pode pensar aqui para que as homenagens aconteçam, giram em torno das trajetórias pessoais dos homenageados, a necessidade de denominação de endereços novos e a urgência por afirmação de um sentimento de polonidade por parte de representantes da comunidade. Pontos estes que serão confirmados ou não em um estudo mais aprofundado, ainda em curso.

\section{Referências}

BAHL, Miguel. Imigração como Potencialidade Turística. In: Revista Turismo em Análise, São Paulo, v. 5. n. 2. 1994. p. 21-32.

BOSCHILIA, Roseli. org. Reconstruindo Memórias: os poloneses do Santo Inácio. Curitiba: Universidade Tuiuti do Paraná, 2004. 
IANNI, Octavio. Do polonês ao polaco. In: IANNI, Octavio. Raças e classes sociais no Brasil. São Paulo: Civilização Brasileira, 1966, p. 117-146.

NICOLAS, Maria. Alma das Ruas. Curitiba: Imprensa Oficial do Estado do Paraná, vol. I, 1969.

OLIVEIRA, Márcio de: Organizações sociais dos Imigrantes Poloneses e seus descendentes em Curitiba (Brasil, 1890-1938). In: E/imigrações: histórias, culturas, trajetórias. LIMA, Ismênia de, HECKER Alexandre, org. $1^{\circ}$ ed. São Paulo: Expressão e Arte editora, 2010. p. 83-99.

ROCHA, Rafaela Mascarenhas. Curitiba Polonesa?: Um estudo sobre logradouros públicos dedicados a imigrantes e descendentes de poloneses (1951-2008). 2016. Dissertação (Mestrado em Sociologia) - Programa de Pós Graduação em Sociologia, Universidade Federal do Paraná, Curitiba, Paraná, Brasil.

SEYFERTH, Giralda. Os Imigrantes e a Campanha de Nacionalização do Estado Novo. In: Repensando o Estado Novo. PANDOLFI, D. org. Rio de Janeiro: Editora Fundação Getúlio Vargas, 1999. p. 199-228.

WACHOWICZ, Ruy Cristovam. Orleans: Um século de Subsistência. Curitiba: Edições Paiol, 1976.

. Saporski: um pioneiro polono brasileiro. Revista Projeções, Curitiba, ano II, 2000, p. 107-146.

\& MALECZEWSKI, Zdzislaw. Perfis Polônicos no Brasil. Curitiba:

Vicentina, 2000. 